\title{
Building Community Among Black Physicists
}

\author{
At the National Society of Black Physicists conference, attendees \\ emphasize the importance of a supportive research community.
}

By Erika K. Carlson

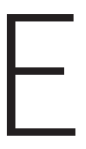
ach year, the National Society of Black Physicists (NSBP) congregates for a conference full of research talks, plenary sessions, workshops, and networking opportunities. This year's meeting, held online earlier this month, hosted a slew of research presentations from condensed matter to cosmology. But for attendees, it was also a place to work on building community with their fellow physicists.

And from speakers' remarks to the awards presentation to the involvement of students in planning and hosting sessions, the conference seemed to focus especially on supporting students and early-career researchers. "Our students become the next presidents, the next leaders of our community," said Stephon Alexander of Brown University, Rhode Island, the current NSBP president, while moderating a Q\&A session. (Alexander also gave a talk about his second life as a musician. See Physics Lessons from the World of Music.)

Farrah Simpson, a graduate student at Brown University,

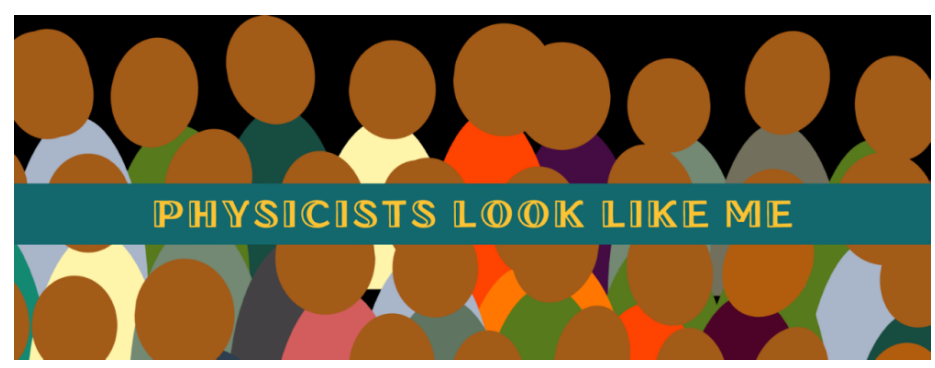

The National Society of Black Physicists (NSBP) conference was virtual this year but still managed to create a supportive environment for early-career scientists.

Credit: T. Coleman appreciates the encouraging culture of the NSBP conferences. "There's a huge emphasis on every level supporting other levels-like professors supporting postdocs, postdocs supporting graduate students."

Some physicists have been hooked on the unique opportunities that the NSBP conference provides since their first conference. "I remember being really amazed, being in a roomful of hundreds of Black physicists," said Charles D. Brown II of the University of California, Berkeley, about attending his first NSBP meeting in 2015. "I remember feeling really empowered and refreshed, and l've made it a point to go every year since then."

This year's conference was still extremely valuable, Brown said, even though there wasn't a physical "room" to share with fellow attendees. "It provides this sort of unique space where Black physicists can just go and be physicists," he said.

And part of being a physicist is discussing the complexities of nature. At the opening plenary session, Yale University particle physicist Larry Gladney gave a sweeping overview of the history, current state, and potential future of fundamental particle physics. Before diving into his discussion of the directions the field might go, he shared a message to students in the audience-that this is "a future that needs your talents and your work to advance the frontiers of knowledge."

Another plenary session featured a conversation between Alexander and physicist-turned-entrepreneur Lisa Dyson. Dyson began her career as a string theorist but is now founder and CEO of two startup companies focused on climate change and sustainability issues. When asked if she had any advice for students, she replied that, whether in research or business, it's 
important to surround yourself with people who are good to work with. "Find those who are supportive and run from those who aren't," she said.

The final plenary talk was given by Sethuraman Panchanathan, the current director of the National Science Foundation. He stressed the importance of building support networks at the institutional level and making science more welcoming to all. "We are missing talent because we are not inclusive enough," he said.

The NSBP conference put great emphasis on fostering its student talent. "This year, they made a huge effort to make students very involved in the planning and execution of the conference," said Simpson, who is the student representative on the NSBP Board. Part of the planning involved a promotional video for the conference, in which some young physicists talked about their past experiences with NSBP. And students were also center stage at an awards ceremony on the last day of the conference. Roughly a dozen students were recognized either for oral talks or posters presented that weekend or for taking top places in a "Three-Minute Thesis" competition organized by the Black In Physics initiative and sponsored by NSBP.

After the conference's close, Simpson said she wants to continue being involved in the community. "In the same way that older professionals in NSBP have mentored me and taught me so much, I also want to do that for younger graduate students," she said. And as an international student from Jamaica, she said she hopes NSBP will become known outside the US and throughout the Caribbean as well.

Brown also encourages non-Black physicists to attend future NSBP conferences. "NSBP is not just for Black physicists," he said. "It's really an awesome conference where you will learn a lot of really interesting physics and meet a lot of the people doing the important work. So everybody should go."

Erika K. Carlson is a Corresponding Editor for Physics based in New York City. 